\title{
Teaching the Design Process in a HyFlex Environment
}

\author{
Cecelia M. Wigal \\ University of Tennessee at Chattanooga
}

This paper addresses how one instructor redesigned a face-to-face design course - Introduction to Engineering Design (IED) - known for its collaborative and experiential learning focus to accommodate a synchronous hybrid flexible (HyFlex) delivery. In semesters prior to spring 2020, students in IED learned the design process by practicing it using a project supported by clients and customers in the local community. Due to Covid19, however, students during the 2020 spring and fall semesters and the 2021 spring semester could not physically meet with traditional clients, which is integral to the experiential aspect of the course. It was also difficult for students to physically meet consistently in teams. These alterations had the ability to negatively affect the learning experience. Thus, the collaborative nature of the class and the client identification and interaction structure was revised. This paper describes the course design process focus, project and client identification, and team collaboration process used in the HyFlex delivery to aid learning of the design process.

Keywords: freshman design, online design, HyFlex design

\section{INTRODUCTION}

Traditional face-to-face (f2f) design-based courses most often have a team focus where students participate in many collaborative activities. These activities address problem and user need identification as well as solution generation, selection, build, and test. Traditionally, the supporting activities occur in the classroom in small groups or out of the classroom in team or client meetings. However, the Covid19 environment forced many traditional $\mathrm{f} 2 \mathrm{f}$ courses to occur in on-line and hybrid flexible (HyFlex) modes. This caused those who teach design-based courses to rethink how collaboration and interaction occurs in an environment that requires physical distancing and synchronous and asynchronous on-line participation.

This paper addresses how one instructor redesigned a $\mathrm{f} 2 \mathrm{f}$ freshman introduction to design course known for its project-based, collaborative, and experiential learning focus to accommodate a synchronous HyFlex delivery. In semesters prior to fall 2020, students in the course worked through the design process to build a solution for an individual with a disability to help the individual be independent. The clients for these projects were young people in local schools, adults in local adult-care facilities, and children and adults in a regional Special Olympics chapter. After fall 2019, due to Covid19, students could not meet with clients in the community or visit local schools or local adult and child-care facilities. However, students having clients and customers from whom they hear of and observe problem issues is an integral part of the design process and this specific freshman design course. This loss of community clients was most difficult to overcome in the Covid19 environment and move to the HyFlex course offering. 
In addition, the move to HyFlex course offerings made traditional in-class small group activities inconvenient and ineffective. In the past, in-class activities may include whiteboard use, small group interactions, and group presentations. Collaborative activities may include group table interaction exercises, brainstorming, and problem solving. The HyFlex environment required that these interactions be reevaluated to allow for $\mathrm{f} 2 \mathrm{f}$ and on-line synchronous participation. The desired results were (1) successful learning of the design process and (2) successful completion of projects developed through productive team collaboration.

Since the Covid19 environment evolved from spring 2020 through spring 2021 the instructor had the ability to further revise the course and project interactions to improve learning.

\section{BACKGROUND}

Spring 2020 was the first semester the instructor was required to teach a freshman design course using a flexible synchronous/asynchronous on-line teaching mode. In fall 2020 and spring 2021, the instructor taught the same course in a fully HyFlex mode with both $\mathrm{f} 2 \mathrm{f}$ and synchronous and asynchronous on-line students. The instructor has taught the freshman design course for over 16 years.

\section{HyFlex Teaching}

In a HyFlex teaching and learning environment, students are free to decide how they will participate in class - either f2f, on-line, or a combination of the two (Beatty, 2020). Because of this, the instructor must provide both on-line and $\mathrm{f} 2 \mathrm{f}$ experiences that are both effective and equitable for the students. This is challenging. It is particularly challenging because the instructor may not know who is in the $\mathrm{f} 2 \mathrm{f}$ class each day. Another challenge is ensuring students are engaged in a single learning community no matter how they are flexing their participation mode (Beatty, 2020).

The structure of a HyFlex course is built around four principles: Learner Choice, Equivalency, Reusability, and Accessibility (Beatty, 2007). Learner choice is where students choose how they attend and participate in the course week to week or even day to day. At the instructor's university the students could participate in-class and either synchronously or asynchronously on-line, depending on their Covid19 health or environment adversity.

Equivalency means that the learning activities of each participation mode allow for equivalent learning - reflective learning, interactive learning, and collaborative learning. All modes should allow students to contribute to the course discussion so reflective, interactive, and collaborative learning can occur. Creating an equitable environment where all students can achieve the stated course outcomes is a major challenge of HyFlex teaching (Binnewies \& Wang, 2019).

Reusability emphasizes that artifacts used for and doing the learning activities for all participation modes be available to all students following those activities (Beatty, 2007). Thus, course sessions and collaborative student activities should be captured and posted to the course management site. If physical handouts are used, they should also be available electronically. All announcements should be shared in $\mathrm{f} 2 \mathrm{f}$ and on-line modes. This also means that activities that occur on-line only (such as on-line chats, asynchronous discussions, and peer reviews), should be captured so that f2f students can access the material.

Accessibility, which is not necessarily something instructors control, must occur for HyFlex teaching to work. Students who desire to flex their participation must have the technology for, skills for, and physical access to the participation modes. This may require the institution to provide technology or software or the instructor to use on-line available software or tools to increase access.

Presently there is little research on the effectiveness of HyFlex teaching. However, one study indicates that HyFlex mode student completion rate can be almost as high as that for the $\mathrm{f} 2 \mathrm{f}$ mode and can be much higher than that for the traditional on-line only mode (Binnewies \& Wang, 2019). Other studies state that the HyFlex participation mode shows promise because students like the flexibility it provides (Beatty, 2007) (Binnewies \& Wang, 2019). It is noted that emphasizing equity in equivalence, reusability, and accessibility is important in creating a successful HyFlex environment (Beatty, 2007). 


\section{Design Process and Thinking}

Teaching in a HyFlex environment is challenging. Teaching design in a HyFlex environment adds additional complexity. This is because design itself is complex. It involves working through a process that requires the designer to thoroughly understand a problem, identify and understand needs of a client(s) and customer(s), and identify the range of applications and use environments. It also involves iteration of progress while developing possible solutions, testing ideas, prioritizing client and customer needs, and finalizing the solution. It then requires modeling, documenting, and building and more testing to take the proposed solution to a deliverable product. And to top it off, most of this is done in a collaborative team environment.

Working through the design process requires a student to assimilate and participate in being a design thinker. Design thinking is activity-based and uses many hands-on methods (Dam \& Yu Siang, 2020). But what makes design thinking so essential to the engineering design process is its emphasis on developing an understanding of the people for whom the service or product is being designed and the environment in which it is used. It especially emphasizes that the designer should develop empathy with respect to the product user (Dam \& Yu Siang, 2020). This emphasis on a system's or process' human foundation is known to lead to better products, services, and processes ("What is Design Thinking", n.d.). This is one reason user and client interactions are so integral to the design process.

\section{The Freshman Introduction to Engineering Design (IED) Course}

The mission of the subject freshman design course - Introduction to Engineering Design (IED) - is to provide an experience so freshman students are introduced to the design process, gain experience in applying the design process, and assimilate knowledge to apply the design process in later courses. Due to this mission, the primary goals of IED are to

expose students to (1) problem definition, (2) customer interaction, (3) attribute generation, (4) function, constraint, and objective identification, (5) idea generation, (6) creative thinking, (7) simple decision-making and (8) idea to reality transformation.

The goals are achieved using a real-life application - improving an entity. In most cases the entity is a device that helps persons with a disability become more independent. Project teams typically have community customers or clients and a budget. Individual and team-based hands-on activities are used to aid the learning.

IED meets 2 times a week for 2 hours each meeting time. Prior to fall 2020, the first 7 weeks of the class were dedicated to the class working together on a virtual project to learn the components of the design process. For the last 7 weeks, the class broke into small teams of 4 to 5 students to understand, design, build, and deliver a solution for an actual customer's problem - thus working from client need to product delivery. Prior to spring 2020, the culmination of the course was an operating and functional device delivered to the client or customer. Student reviews indicate the production of a delivered product is essential to their learning of the design process.

\section{THE IMPACT OF HYFLEX TEACHING MODE ON THE IED STRUCTURE}

The author spent the summer of 2020 investigating how to apply the HyFlex teaching mode to a projectbased collaborative curriculum in anticipation of the effect of the Covid19 environment on the class attendance policies. The author chose the HyFlex mode for the IED course due to its ability to respond flexibly to reactions to the Covid 19 environment including

- students choosing to not attend $\mathrm{f} 2 \mathrm{f}$ courses

- students being isolated or quarantined

- the University moving to $100 \%$ online courses

- the University switching between a closed and open campus 
The HyFlex mode, as well as the Covid19 environment, however, result in restrictions on student interactions with each other and project customers and users. Specifically, students were unable to (1) meet with customers at regional schools and service facilities as was possible prior to spring 2020 and (2) work closely in teams around a table, sharing technology, paper, and writing implements.

To work within the HyFlex mode and the restrictions of the Covid19 environment the IED curriculum was revised to make it more flexible. Also, on-line tools were introduced for class session interactions and project team collaboration.

\section{Curriculum}

The major change for the course deleted the first 7-week virtual project and moved directly to the handson customer supported $2^{\text {nd }}$ project. This was done to initiate team interaction and collaboration before the campus may close. The underlying goal for this was to build a team foundation, especially since this may be the students' first or second semester, to help students communicate as a team in a possible virtual environment.

Because of the change to teach the design process using the single project, the instructor identified which design process components and activities are essential and applicable for student learning. The components identified are (1) satisfying needs of a real customer, (2) identifying design criteria (functions, objectives, and constraints), (3) generating solution possibilities, (4) determining best solutions options, and (5) testing functional concept effectiveness (Dym et.al., 2014). Prior to fall 2020, much emphasis was put on the team-based design build, but this component was de-emphasized for the HyFlex course in fall 2020 since a build could not be guaranteed. However, the build was emphasized again in spring 2021 since the Covid19 environment evolved and students were allowed use of the maker space.

Also, prior to fall 2020, most project assignments were team related. The newly designed HyFlex IED curriculum, however, includes the team project but puts more emphasis and responsibility on individual work products - assignments are now 50\% individual and 50\% team produced. Table 1 summarizes the project assignments. The ability to create a working final project is embedded in the final project presentation.

TABLE 1

HYFLEX COURSE ASSIGNMENT DISTRIBUTION

\begin{tabular}{|c|c|c|c|}
\hline \multicolumn{2}{|c|}{ Assignment } & \multicolumn{2}{|c|}{ Responsibility } \\
\hline$\#$ & Description & Individual & Team \\
\hline 1 & Student problem selection proposal and user identification & 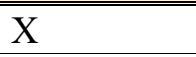 & \\
\hline 2 & $\begin{array}{l}\text { Student problem research to identify history, present designs, and } \\
\text { client/customer needs. }\end{array}$ & $\mathrm{X}$ & \\
\hline 3 & Project definition that formalizes project purpose and design criteria & & $\mathrm{X}$ \\
\hline 4 & Individual solution generation & $\mathrm{X}$ & \\
\hline 5 & Team-based solution generation & & $\mathrm{X}$ \\
\hline 6 & Initial design solution selection decision & & $\mathrm{X}$ \\
\hline 7 & Concept prototype/model design & $\mathrm{X}$ & \\
\hline 8 & Concept prototype/model test process & $\mathrm{X}$ & \\
\hline 9 & Concept prototype/model test results & $\mathrm{X}$ & \\
\hline 10 & Final solution prototype status report & & $\mathrm{X}$ \\
\hline 11 & Final solution prototype presentation & & $\mathrm{X}$ \\
\hline 12 & Final solution design report & & $\mathrm{X}$ \\
\hline
\end{tabular}

The goal of the individual assignments is to initiate project understanding, project solution brainstorming, and concept modeling and testing prior to team final project integration so individuals can 
better contribute to team final design decision making. The other goal is to ensure project design solution generation and concept prototyping occur if the course goes $100 \%$ on-line prior to the end of the semester.

Design problem initialization was also affected by the conversion to the HyFlex curriculum. Prior to fall 2020, the instructor identified projects and project clients and customers. However, after spring 2020, the instructor identified specific design problems for the students to consider addressing. Most of the problems did not have specific clients or users. Students had the responsibility to identify two projects they preferred to address for the semester as well as possible users or clients they could contact to aid in need identification and prototype testing. The students were instructed to ensure they can interact with the contacts in the Covid19 environment especially if the course were to go $100 \%$ on-line. In spring 2021 a few projects had predefined clients and users since these projects had outside applications that could be addressed in the evolved Covid19 environment. Once the design problem preferences were identified, the instructor placed the students in teams based on their preferences, with most students working their most preferred design problem. Most projects involved solving issues for persons with physical disabilities or conditions such as severe arthritis. Student teams of 3 to 5 students were assembled. This resulted in at least 3 possible users or clients per project.

\section{Teaching Tools}

Another course modification was to replace all in-class collaborative and interactive activities with ones that could be completed and shared in an on-line collaborative environment. This required using software that makes material and activities accessible to all students such as Zoom, Canvas, Microsoft Teams and Forms, and Aww App (Aww App was recently acquired by Miro and is no longer available). Table 2 summarizes the collaborative and interactive activities and software and technology used in HyFlex IED. All class activities and class sessions, including class lessons, are captured, and posted on the course management system.

TABLE 2

SOFTWARE AND TECHNOLOGY SUPPORT FOR CLASS ACTIVITIES

\begin{tabular}{|l|l|}
\hline Activity & Software and Technology \\
\hline Research summary and criteria identification & Aww App/Miro \\
\hline Empathy mapping & Aww App /Miro \\
\hline Brainstorming using Heuristics & Canvas Quiz \\
\hline Objective and function wording and diagramming & Zoom White Board and Surface Pro \\
\hline Presentations & Zoom Screen Sharing \\
\hline Team meetings and document sharing & Microsoft Teams \\
\hline Individual findings and brainstorming sharing & Canvas Assignment Peer Review \\
\hline Student assessment of peer presentations & Microsoft Forms \\
\hline Class lectures and learning sessions & Surface Pro, Smart Pen, MS OneNote \\
\hline
\end{tabular}

Zoom

Zoom was used for connecting on-line students to the in-class sessions. Zoom breakout rooms were used for small group in-class activities. Microsoft (MS) Teams, however, was preferred for team-based activities and communication. MS Teams provides a platform for project teams to meet visually and verbally. A benefit of MS Teams is that it provides a location for maintaining and sharing project documentation. Recordings of meetings can also occur and communication in the on-line chat space is preserved.

\section{Learning Management System (LMS)}

Canvas is the learning management system (LMS) used by the author's University. Since not all students participate in the IED f2f class sessions, it is necessary to provide class session activity access, 
instructions, and materials electronically using Canvas. This involves posting instructional materials as done in the past, but Canvas is now also used to initiate collaboration activities for interaction of $\mathrm{f} 2 \mathrm{f}$ students with on-line students. For example, one activity used to help student teams brainstorm design options requests teams to expand their collection of possible solutions by using at least three Design Heuristics developed by Yilmaz et.al. (Yilmaz et.al., n.d.). In the past students would blindly choose three Design Heuristic cards from a physical stack. Now the Design Heuristics are provided to the students using the quiz function in Canvas. The heuristics quiz presently houses 23 Design Heuristics. When a member of the team opens the quiz, the team is provided 5 randomly selected heuristics from the 23 . The team is directed to use 3 of these Design Heuristics to expand their collection of brainstormed solutions by at least 3 . Teams may use collaboration tools such as Aww App/Miro to complete the activity. Samples of Design Heuristics are shown in Figure 1.

\section{FIGURE 1 \\ DESIGN HEURISTIC EXAMPLES}

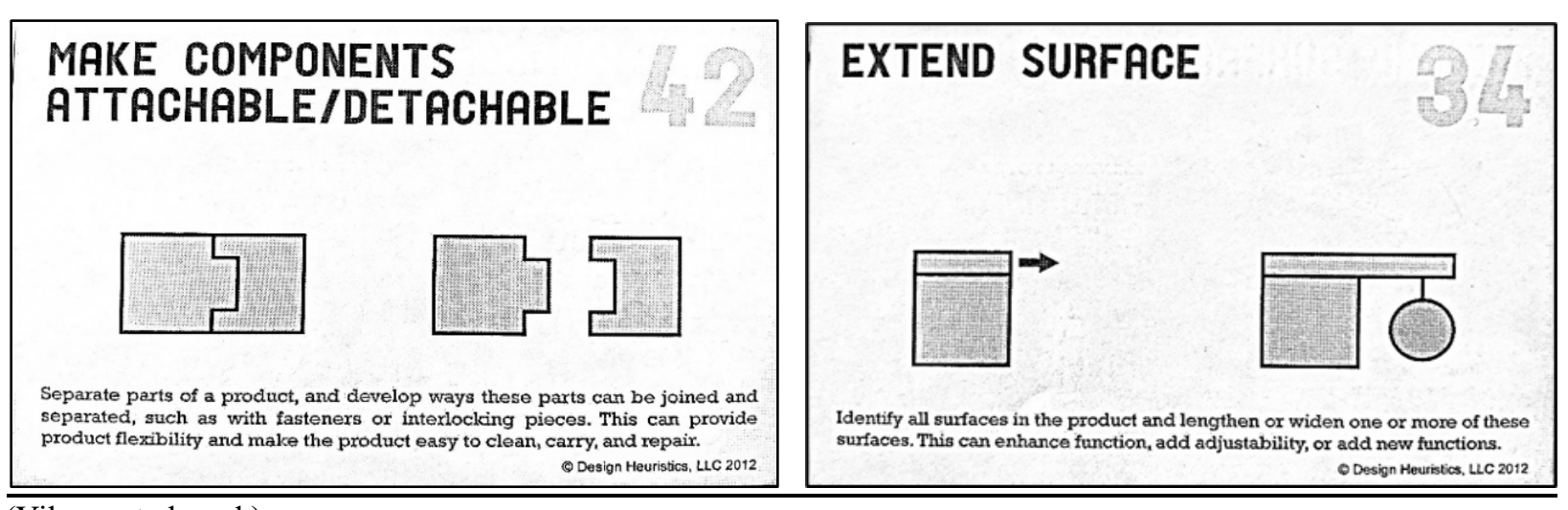

(Yilmaz et.al., n.d.)

In addition to the Canvas quiz function for student interactions, the Canvas discussion and peer review applications are used to solicit student feedback for student activities and collaboration initiation. For example, the peer review application is used when students assess specifically assigned individual project research contributions submitted as assignments. The Canvas discussion application is used to solicit responses from the project teams or the entire class on class activities. Prior to 2020 these responses occurred in small group $\mathrm{f} 2 \mathrm{f}$ discussions within the classroom.

Canvas is also used to initiate asynchronous student responses to individual and team contributions such as for those activities described below.

\section{Collaboration White Board Platform}

Since interaction between students is necessary in design, and on-line and $\mathrm{f} 2 \mathrm{f}$ students must interact synchronously and asynchronously, an on-line collaboration board was identified for team use. Aww App and Miro house virtual collaboration platforms that allow students to work individually or simultaneously to interact and work in a white space using freehand sketching, post it notes, block diagramming, and document and figure insertion (Aww Board, n.d.) (Miro, n.d.). For IED, the Aww App platform, and now the Miro platform, allow in-class and on-line students to collaborate during course and team meetings to communicate research findings and criteria identification, and to participate in brainstorming activities. Figure 2 is a download of an Aww App whiteboard result for a class activity where students identify project research findings and convert the findings into design objectives. All students contribute to the research comments and objective identification by opening the Aww App link on the course Canvas class session page and typing their response. There is some delay when watching the contributions, but it does not negatively affect the results of the activity. 
The Aww App and Miro platforms also have embedded templates useful for collaborations. One example is the Empathy Map template. Figure 3 is a result of a team assignment to create an Empathy Map to aid in identifying user needs related to user feelings, tasks, influences, pain points, and use goal. The application of this map is a COVID19 mask for individuals who do not have full use of their hands or arms. The team worked together in the virtual environment to complete this template by imagining themselves as the user. Team members participated synchronously by creating sticky notes and placing them in the appropriate location on the template. Sticky notes can be color coded to indicate which student provided which comment.

FIGURE 2

\section{AWW APP EXAMPLE - OBJECTIVES IDENTIFICATION FOR IMPROVING STUDENT ACCESS CARD}

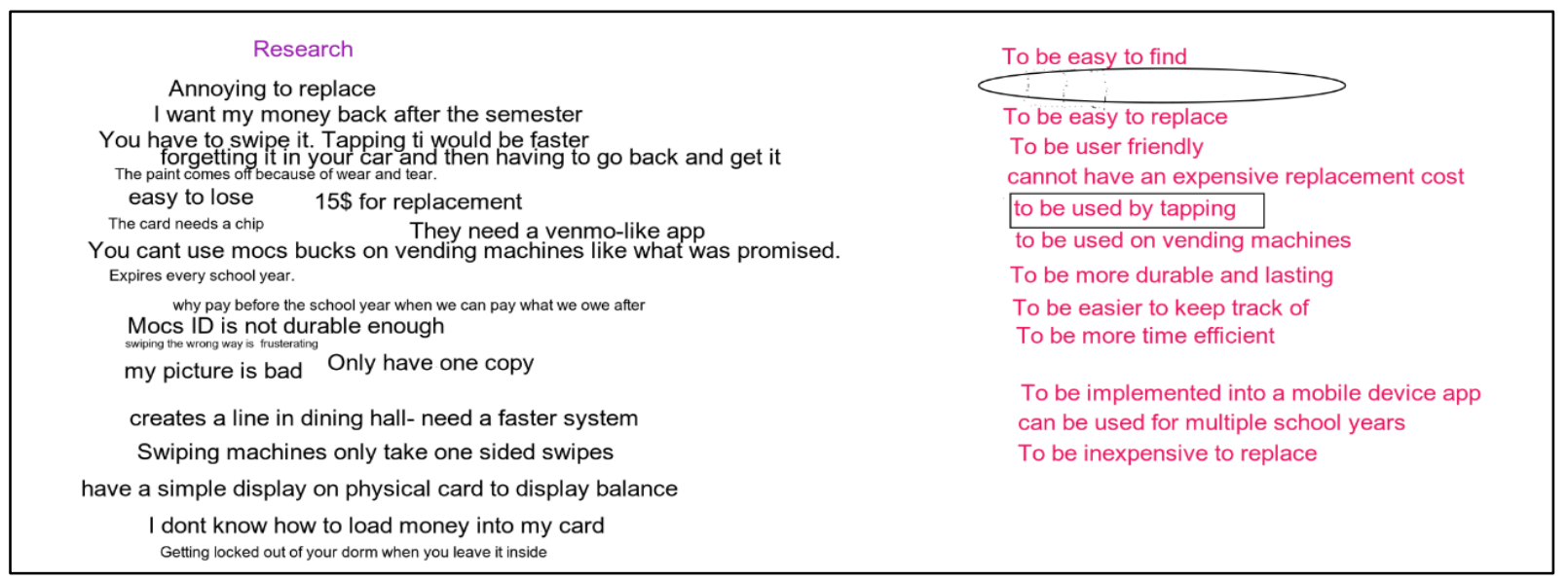

FIGURE 3

EXAMPLE OF STUDENT GENERATED EMPATHY MAP USING AWW APP

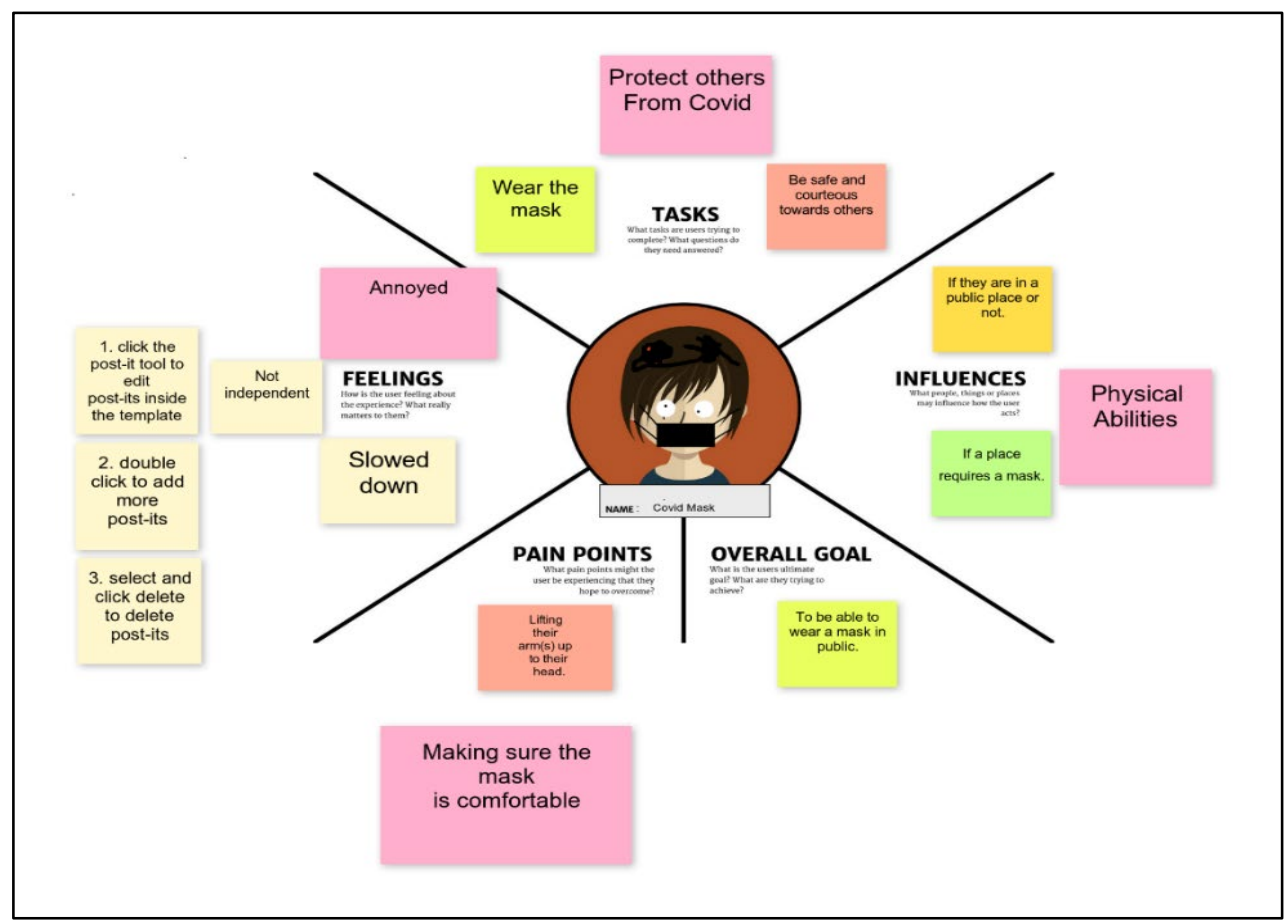




\section{Microsoft Forms}

Microsoft (MS) Forms also provides a means to solicit student feedback. In IED, MS Forms is used by students to submit peer reviews of individual and team presentations. The instructor developed a simple form using a 5-point rating scale. A link to the form is made available to students on the course Canvas site as part of the weekly instruction and activity section. Students can easily access the link using a desktop computer, tablet, or phone. The link can also be made available by the instructor using the Zoom Chat function, so students do not have to access the class Canvas site. Thus, on-line and $\mathrm{f} 2 \mathrm{f}$ students can immediately provide feedback to peer presentations upon presentation completion. MS Forms allows the instructor to capture and analyze the feedback using MS Excel which results in prompt feedback to the presenter and teams.

\section{Teaching White Board}

A large change for the instructor during the Covid19 environment was the loss of the whiteboard for class lessons. (This occurred because the classroom camera was not sufficient to record physical whiteboard activity.) A Surface Pro, a Smart Pen, and MS OneNote substituted for the traditional whiteboard. The MS OneNote screen was shared in Zoom for the on-line students and the Zoom screen was projected in the class for the in-class students.

\section{Reactions to Collaborations and Interactions}

Students took to using the Aww App whiteboard quickly; however, they at times strayed from the assigned task because they found it fun to "play" with the provided functions, especially accessing and drawing on other teams' whiteboard pages. To alleviate opportunities for these occurrences the instructor limited the whiteboard to one page and provided each team a unique Aww App link and thus a unique whiteboard. This resulted in teams focusing more on the activity than playing with the platform.

The most successful use of the Aww App was the empathy mapping. In their review of the experience many students mentioned this activity as being beneficial to their solution generation. Fall 2020 was the first semester for this activity. It was a substitute for a similar f2f activity completed in previous semesters which did not adapt well to HyFlex. The empathy mapping activity was repeated in spring 2021, again with positive results and feedback. Students stated that putting themselves in the "shoes" of the user opened their minds to barriers of success in their previous solutions and to possible solutions they would not have considered otherwise. The ability to use the template aided in the success of this activity.

The other successful activity was the use of the Design Heuristics to increase the solution generation space. Prior to fall 2020 the Design Heuristics were used as a suggestion to aid solution generation. Beginning fall 2020 and continuing through spring 2021 it became a specific assignment. The students took ownership of this assignment - receiving randomly selected 5 heuristics and choosing 3 they wanted to apply. Students also commented in their experience review that this assignment was beneficial to expand their design space. The Design Heuristics forced them to think about possibilities that were not previously considered - individually or collaboratively.

The most beneficial and possibly most important change to IED for the HyFlex format was the strong emphasis on the individual assignments associated with the team project. This allowed the teams to view their project solutions as a system with subsystems that required modeling and testing prior to system prototype creation. It also ensured each student had practice testing and improving a physical model they created from an abstract solution. Students commented in their experience review that the opportunity to build and test and rebuild illustrated the iterative nature of the design process.

Although there are positive outcomes to the Covid19 adjusted course with respect to course activities, students were not enthusiastic about all changes. Specifically, students did not enjoy working in teams using the virtual format. This is mostly due to on-line students not being visually present in class or team meetings. It was observed that on-line students did not use their camera function to be present in class sessions and team meetings. This caused $\mathrm{f} 2 \mathrm{f}$ students to feel disconnected from on-line team members.

Team interaction was also not always effective. In fall 2020 it was suggested that teams use MS Teams to enhance interaction; however, only a few teams took advantage of the platform. In spring 2021, the MS 
Teams platform was required, though not all teams took advantage of its collection of interactive and document sharing capabilities. The instructor assumed the students could self-learn how to use the capabilities - this was an incorrect assumption. More instruction on MS Teams will be provided in future semesters.

\section{CONCLUSION AND COURSE IMPROVEMENTS}

Fall 2020 and spring 2021 HyFlex IED were successful with respect to student learning as illustrated by final exams and individual and team presentations. The learning that occurred during the individual model building and testing was much increased from what occurred in previous semesters. The structure forced students to be more individually accountable to the project because they were assessed on their ability to model and test their assigned subsystems. In addition, students participated in class sessions using the collaborative whiteboards. Also, progression of lessons was successfully presented using the Surface Pro, Smart Pen, and MS Onenote.

However, in the fall 2020 HyFlex class experience, team interactions suffered. Previously, teams spent class time working together in a physical space sharing ideas, building in the shop, and composing assignment responses. But, in HyFlex, some on-line students chose to maintain not only physical distance, but also communication distance. This negatively affected team outcomes as well as their own learning. To help improve interactions the spring 2021 on-line students were instructed to use cameras in class sessions and team meetings. This started the first day of the course when the students used Zoom and Google Slides to introduce themselves and share one aspect of themselves they believe important. An example of a student generated share slide is shown in Figure 4. This single activity increased student interactions because students learned of peer commonalities be it from the Google Slide presentation or a poster or personal item sitting in camera view. Following this activity, the instructor found students freely interacting in the Zoom environment - with cameras on - before, during, and after class.

FIGURE 4

\section{SAMPLE STUDENT SHARE GOOGLE SLIDE}

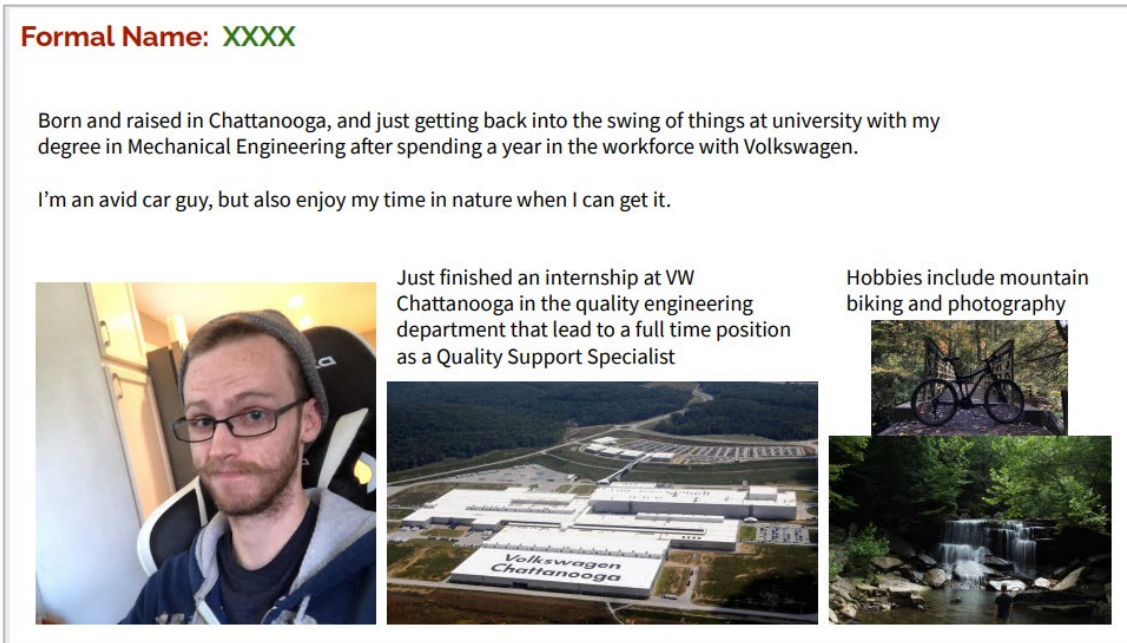

The fall 2020 students did have one complaint about the HyFlex IED project process. They did not appreciate having the responsibility of finding their own users/clients/customers for the provided projects. The instructor acknowledges this is not optimal. Due to this, most of the projects for the spring 2021 course were introduced with suggestions for users/clients/customers and a few had specifically identified customers (where physical distancing and outdoor meetings were guaranteed). It is hoped that future 
projects will have identified customers and clients so students can focus more on learning about customer needs than customer identification.

\section{REFERENCES}

Aww Board. (n.d.). Aww App. Retrieved September 2020, from https://awwapp.com/

Beatty, B.J. (2007). Hybrid classes with flexible participation options - If you build it, how will they come? $30^{\text {th }}$ Annual Proceedings: Volume 1: Annual Convention of the Association for Educational Communications and Technology, pp. 15-24.

Beatty, B.J. (2019). Teaching a Hybrid-Flexible Course: The Faculty Experience in HyFlex. HybridFlexible Course Design. Hybrid-Flexible Course Design. EdTech Books. Retrieved December 5, 2020, from https://edtechbooks.org/hyflex/teaching_hyflex

Binnewies, S., \& Wang, Z. (2019). Challenges of Student Equity and Engagement in a HyFlex Course. Blended Learning Design in STEM Higher Education, pp. 209-230. Springer Nature Singapore Pte Ltd.

Canvas Learning Management System. (n.d.). Retrieved September 2020, from https://www.instructure.com/canvas

Dam, R.F., \& Yu Siang, T. (2020). What is Design Thinking and Why is it so Popular? Interactive Design Foundation. Retrieved December 2, 2020, from https://www.interactiondesign.org/literature/article/what-is-design-thinking-and-why-is-it-so-popular

Denayer, I., Thaels, K., Vander Sloten, J., \& Gobin, R. (2003). Teaching a structured approach to the design process for undergraduate engineering students by problem-based education. European Journal of Engineering Education, 28(2), 203-214.

Design Thinking Defined. (n.d.). IDEO. Retrieved December 2, 2020, from https://designthinking.ideo.com

Dym, C.L., Little, P., \& Orwin, E.J. (2014). Engineering Design: A Project-Based Introduction (4th edition).

IDEO U. (n.d.). What is Design Thinking. Retrieved December 2, 2020, from https://www.ideou.com/blogs/inpsiration/what-is-design-thinking

Liedtka, J. (2018). Why Design Thinking Works. The Magazine, Harvard Business Review.

Miro. (n.d.) Retrieved July 26, 2021, from https://miro.com

Wigal, C.M., \& McMahon, E. (2003). Introducing Freshmen to the Design Process. 2003 ASEE Southeast Section Conference Proceedings.

Wigal, C.M., McMahon, E., \& Littleton, M. (2008). Measuring the Benefit of Service Oriented Student Design Projects. In $38^{\text {th }}$ ASEE/IEEE Frontiers in Education Conference Proceedings.

Yilmaz, S., Seifert C., Daly S., Gonzalez R., \& Christian J. (n.d.). Design Heuristics - Strategies to Inspire Ideas. Retrieved August 2020, from https://www.designheuristics.com/the-cards/ 